\title{
Early mortality in spontaneous supratentorial intracerebral haemorrhage
}

\author{
N. Samprón*; A. Mendia; B. Azkarate; F. Alberdi; M. Arrazola and E. Urculo* \\ Servicio de Neurocirugía* y Cuidados Médicos Intensivos . Hospital Donostia. San Sebastian. España.
}

\section{Summary}

Background. Spontaneous supratentorial intracerebral haemorrhage is a severe, frequent, and poorly understood condition. Despite the publication of 12 randomised controlled trials on this subject, the role of surgery remains controversial and no treatment has proved to be effective. We report on a ten year prospective cohort study based on a defined population treated with or without surgery and their outcome in terms of early survival.

Methods. Population based, ten year prospective observational study directed to patients consecutively admitted to the Intensive Care Unit (ICU) in a tertiary centre with spontaneous supratentorial intracerebral haemorrhage. Patients were distributed in five groups according to the Glasgow Coma Score (GCS) at admission. Haemorrhages were classified as deep-seated or superficial. All patient received standard medical care, and additionally surgery if it was found indicated by the duty neurosurgeon. Primary endpoint was early mortality defined as dead occurred by any cause during the admission in the ICU.

Findings. During the ten year period, 1.485 patients were admitted to our centre with primary intracerebral haemorrhage. Of these, 376 were admitted to the intensive care unit and 285 sustained supratentorial haemorrhages. Low GCS was strong predictor of early mortality. Despite the larger size of haematomas in patients undergoing surgical evacuation, surgery was associated with lower early mortality in all GCS subgroups. Maximal benefit was observed in patient with admission GCS of 4-8. Superficial haematomas were operated on more often, and were associated with lower mortality rate than deep-seated cases.

Conclusions. Our findings suggest that craniotomy for haematoma evacuation may reduce early mortality in patients with primary supratentorial intracerebral haemorrhage. Surgery seems specially useful in patients with admission GCS between 4 and 8 , and in those with superficial haemorrhages.

Recibido: 25-07-08. Aceptado: 16-11-09
KEYWORDS: Intracerebral haemorrhage. Craniotomy. Hypertension. Early mortality. ICU management. Glasgow Coma Score.

Mortalidad temprana en hemorragia intracerebral supratentorial espontánea

\section{Resumen}

Introducción. La hemorragia intracerebral supratentorial espontánea es un proceso frecuente, grave y poco comprendido. A pesar de la publicación de 12 ensayos clínicos controlados sobre el tema, la indicación quirúrgica es controvertida y ningún tratamiento se ha mostrado efectivo. Presentamos los resultados de un estudio prospectivo de cohortes desarrollado a lo largo de diez años en una población definida. Los pacientes recibieron tratamiento quirúrgico o conservador y su evolución se describe en términos de mortalidad temprana.

Materialymétodos. Estudio prospectivo y observacional basado en una población definida en el que se incluyeron consecutivamente todos los pacientes que ingresaron a lo largo de diez años en la Unidad de Cuidados Intensivos (UCI) de un centro terciario. Los pacientes fueron clasificados en cinco grupos de acuerdo al puntaje en la escala de coma de Glasgow (GCS) al ingreso. Las hemorragias fueron clasificadas en superficiales y profundas. Todos los pacientes recibieron el tratamiento médico estándar y cirugía de acuerdo con la indicación del neurocirujano de guardia. El punto final del análisis fue la mortalidad temprana, definida como muerte por cualquier causa ocurrida durante el ingreso en UCI.

Resultados. Un total de 1.485 pacientes con hemorragia intracerebral espontánea fueron ingresados en nuestro centro durante los diez años del estudio. De

Abreviaturas. DSA: digital subtraction angiography. GCS: Glasgow coma score. Escala de coma de Glasgow. ICH: intracerebral haemorrhage. ICU: intensive care unit. STICH: surgical trial in intracerebral haemorrhage. UCI: unidad de cuidados intensivos. 
estos, 376 ingresaron en UCI y en 285 la localización fue supratentorial. El puntaje bajo en GCS se mostró como un fuerte predictor de la evolución. A pesar de que los pacientes operados tenían hematomas más voluminosos, el tratamiento quirúrgico se asoció con una disminución de la mortalidad en todos los grupos. Se observó un beneficio máximo en los pacientes con puntaje entre 4 y 8 en GCS. Los hematomas superficiales fueron operados con mayor frecuencia $y$ se asociaron con menor mortalidad que los profundos.

Discusión. Nuestros hallazgos sugieren que la mortalidad temprana en hemorragia intracerebral espontánea puede ser reducida mediante la evacuación quirúrgica de los hematomas. La cirugía parece especialmente útil en pacientes con puntaje inicial en GCS de 4-8 y en aquéllos con hematomas superficiales.

PALABRAS CLAVES: Hemorragia intracerebral. Craneotomía. Hipertensión arterial. Mortalidad temprana. Unidad de Cuidados Intensivos. Escala de coma de Glasgow.

\section{Introduction}

Spontaneous supratentorial intracerebral haemorrhage $(\mathrm{ICH})$ is one of the more severe types of stroke ${ }^{17}$. It is estimated that this condition affects $10-20$ in 100000 people every year with a mortality between $23-58 \%{ }^{1,13,20,21}$. Additionally, only one of five of the survivors regain functional independence at 6 months after ictus $3,13,14,15,20$. There is no definitive evidence to guide treatment but recommendations ${ }^{15,16,20}$. As a consequence, controversy regarding the possible benefit of surgery on these patients persists and thus, there is a considerable variability in the management of this type of stroke $\mathrm{e}^{2,16}$.

The aim of this study was to establish the influence of surgery for haematoma evacuation, and outcome in terms of early survival for patient with spontaneous supratentorial

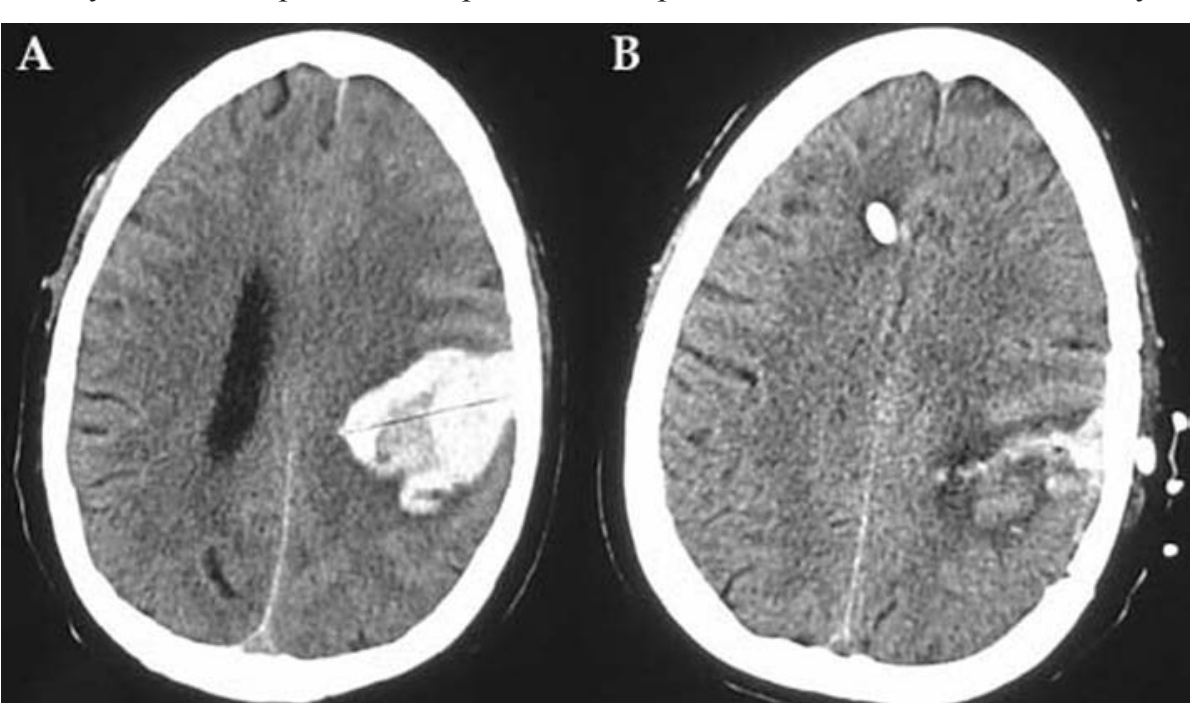

intracerebral haemorrhage in our population.

\section{Patients and methods}

A prospective observational ten years study was conducted in our population based centre with a catchments area of 688,708 inhabitants in Guipúzcoa, Basque Country, Spain. All patients admitted to our general intensive care unit (ICU) with spontaneous supratentorial intracerebral haemorrhage were consecutively included. Informative data of patient who were not admitted to the ICU were obtained from the hospital registry in order to put in perspective our findings. There were no homogeneous criteria for admission in the ICU, but all patients requiring intubation, those deteriorating in wards, and all patient undergoing surgical evacuation of the clot were admitted. Patient with haemorrhage suspected to be secondary were studied with some imaging of the brain vessels, either digital subtraction angiography (DSA), CT angiography, MR angiography or a combination of these methods, and excluded if positive.

Data regarding sex, age, history of hypertension, coagulopathy, Glasgow Coma Score (GCS) at admission, haemorrhage location, volume, ventricular extension, surgery for haematoma evacuation, and early mortality (defined as dead occurred by any cause during the admission in the ICU) were registered.

Haemorrhage location was considered either as deepseated/basal ganglia or superficial/lobar (Figure 1 and 2).

The volume of the haematoma was regarded as either more or less than 50 millilitres as measured by the length $\mathrm{x}$ width $\mathrm{x}$ height $/ 2$ method $^{4}$ on the first CT scan.

The GCS was subdivided in five groups according to a previous exploratory analysis as 3, 4-5, 6-8, 9-12, and 13-15.

All patient received best available medical care and additionally surgery, through a non microsurgical craniotomy, if was indicated by the neurosurgeon.

Statistical analysis was performed with the SPSS 13.0 soft-

Figure 1. Preoperative (A) and $24 \mathrm{~h}$ postoperative (B) CT scan showing a $42 \mathrm{~mL}$ left parietal (lobar or superficial) intracerebral haematoma in a 54 years-old male with history of hypertension. The patient presented with dysphasia, hemiparesis, GCS of 11, and was operated on through a craniotomy within the first 4 hours after ictus. An ICP monitor catheter was also placed. A MR angiography performed two weeks later did not demonstrated any remarkable finding. After one year, the patient remains with dysphasia. 


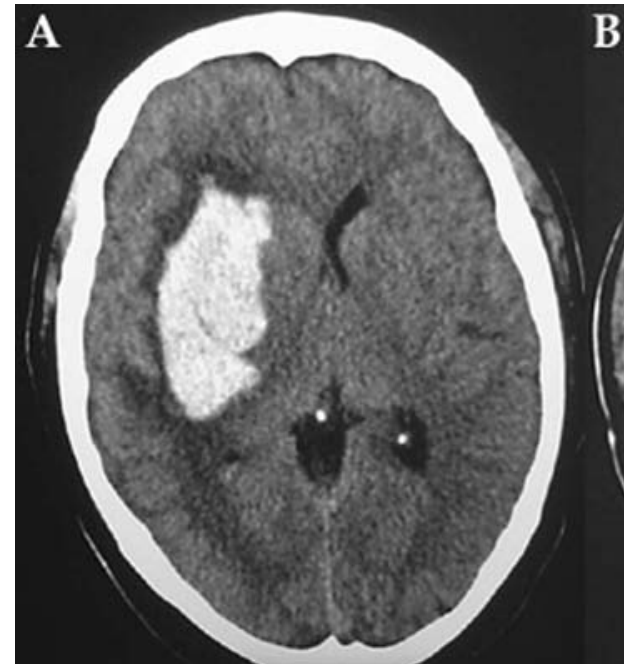

\section{B}

ware for parametric and non parametric descriptive statistics. Comparisons were made by the $\mathrm{t}$ Student test for quantitative variables and the Chi Square test for qualitative variables.

\section{Results}

Between 1997 and 2007, according to the hospital registry, one thousand four hundred and eighty five patients were admitted to our centre after spontaneous intracerebral haemorrhage $(\mathrm{ICH})($ Figure 3). The average age was 69
2010; 21: 93-98

Figure 2. Preoperative (A) and 24 hours postoperative (B) CT scan showing a $35 \mathrm{~mL}$ right putaminal (deep-seated/basal ganglia) intracerebral haematoma in a 37 years-old male with history of hypertension and obesity. The patient presented with hemiplegia and GCS of 13. After 36 hours of admission, he deteriorated and was operated on through a craniotomy. After one year, the patient has moderate disability due to left sided hemiparesis.

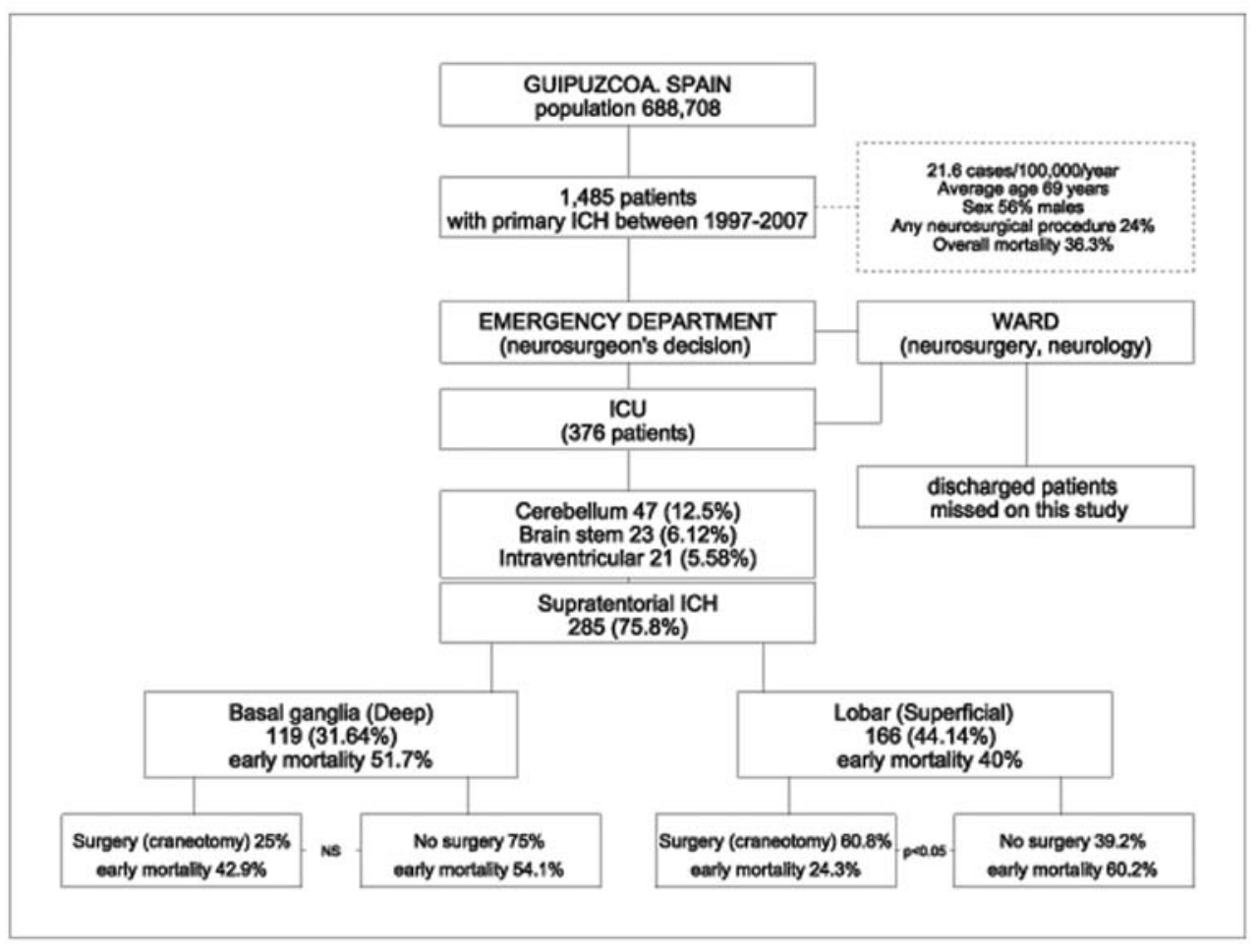

Figure 3. Series profile. Data are number of patients (\%). ICU= intensive care unit. ICH= intracerebral haemorrhage. Data from patient who were not admitted to the ICU comes from the hospital registry. 
Table 1

Baseline characteristic and outcome in 285 patients admitted in the ICU with spontaneous supratentorial intracerebral haemorrhage treated with and without Surgery (medical treatment alone)

\begin{tabular}{lccc}
\hline & Craniotomy & Medical treatment alone & \\
\hline Number of patients & $131(46 \%)$ & $154(54 \%)$ & \\
Superficial location (lobar) & $101(60.8 \%)$ & $65(39.2 \%)$ & $\mathrm{p}<0.05$ \\
Deep location (basal ganglia) & $30(25 \%)$ & $89(75 \%)$ & $\mathrm{p}<0.05$ \\
Volume (more than 50 mL) & $118(90.1 \%)$ & $98(63.4 \%)$ & $\mathrm{p}<0.05$ \\
Ventricular extension & $68(51.9 \%)$ & $119(77.3 \%)$ & $\mathrm{p}<0.05$ \\
GCS admission (mean) & 8.24 & 7.27 & $\mathrm{p}<0.05$ \\
Age (mean) & 59.28 & 62.35 & $\mathrm{NS}$ \\
Sex (males/females) & $85 / 46$ & $100 / 54$ & $\mathrm{NS}$ \\
History of hypertension & $67(50.9 \%)$ & $79(51.1 \%)$ & $\mathrm{NS}$ \\
Impaired coagulation & $32(24.6 \%)$ & $48(31.2 \%)$ & $\mathrm{NS}$ \\
Days in ICU (mean) & 8.47 & 6.83 & $\mathrm{NS}$ \\
GCS at discharge from ICU & 12.29 & 11.83 & $\mathrm{NS}$ \\
Mortality & $36(27.7 \%)$ & $92(59.9 \%)$ & $\mathrm{p}<0.05$ \\
\hline
\end{tabular}

GCS $=$ Glasgow Coma Score. ICU $=$ Intensive Care Unit. Early dead= dead by any cause during the admission in the ICU. NS $=$ no statistically significant.

Craniotomy for haematoma evacuation was performed in 30 patients (25\%) with deep-seated location and in 101 patients $(60.8 \%)$ with superficial or lobar haematomas ( $<<0.05$, RR 1.8, $95 \%$ CI 1.4-2.2). Both groups (operated and non operated) were no comparable. Although, there were no differences in age, sex, history of hypertension, impaired coagulation, or days of admission in the ICU; patient in the surgical group had a more favourable neurological situation at admission (mean admission GCS $8.24 \pm 3.5$ vs. $7.27 \pm 3.9, p<0.05$ ), the haematomas were larger, and were located more often near the cortex (Table 1). The volume of the haematoma was related with the indication of surgery. Of the154 non surgical patients, 98 (63.4\%) had haematomas of $50 \mathrm{~mL}$ or more. By contrast, between the 131 patient who were operated on, $118(90.1 \%)$ had haematomas of
$50 \mathrm{~mL}$ or more ( $\mathrm{p}<0.05$, RR 1.4, 95\% IC 1.2-1.6).

There were no significant differences in early mortality between operated and non operated in the deep-seated haematomas group, but a tendency in favour of surgery (early mortality $54.1 \%$ vs. $42.9 \%, \mathrm{p}>0.05$ ). By contrast, there was a strong significant difference in the group of lobar haematomas also in favour of the surgical group (early mortality $60.2 \%$ vs. $24.3 \%$, $\mathrm{p}<0.05$, RR 2.1, 95\% CI 1.5-3).

Considering the pre-specified GCS subgroups (Table 2 and Figure 4), all patients except two (one of these was operated on) died among those with GCS at admission of 3. In the group of patients with GCS at admission of 4-5, $51.6 \%$ died in the surgical group and $84 \%$ in the non surgical group. For patients with GCS at admission between 6 and 8,

Table 2

Indication of surgery (craniotomy) according to the admission GCS and early mortality in 282 (3 missing) patients admitted to the Intensive Care Unit with Spontaneous Supratentorial Intracerebral Haemorrhage. Data are numbers of patients (early dead)

\begin{tabular}{lccc}
\hline Admission GCS & Craniotomy (mortality) & Medical treatment alone (mortality) & \\
\hline 3 & $5(4)$ & $15(14)$ & NS \\
$4-5$ & $31(16)$ & $57(48)$ & $\mathrm{p}<0.05$ \\
$6-8$ & $41(14)$ & $32(22)$ & $\mathrm{p}<0.05$ \\
$9-12$ & $29(2)$ & $17(3)$ & NS \\
$13-15$ & $24(0)$ & $31(4)$ & NS \\
\hline
\end{tabular}

GCS $=$ Glasgow Coma Score. NS $=$ no statistically significant 

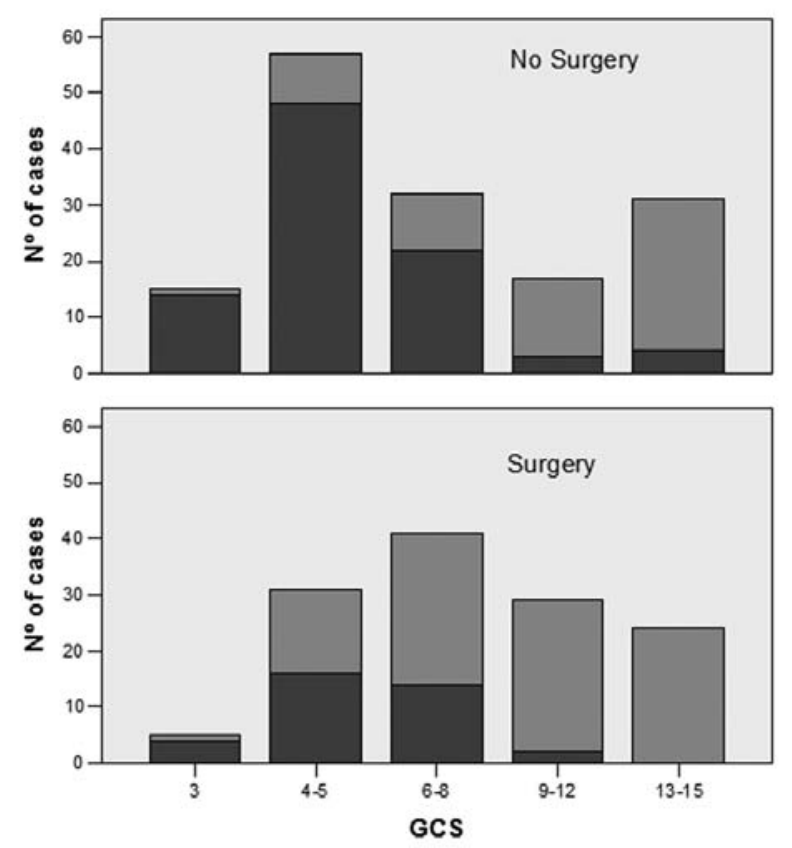

Figure 4. Early mortality according to the Glasgow Coma Score (GCS) at admission. Above. Non surgical group. Below. Operated patients. Deaths are represented in black. Survivors are represented in grey.

mortality was $34.1 \%$ in the patients who were operated on and $68.8 \%$ in the patient who were not operated. In the group with GCS at admission between 9 and 12, 6.9\% died in the surgical group and $17.6 \%$ in the non surgical. Finally, in the group of patient with GCS at admission between 13 and 15, no patient died in the surgical group while four patient (12.9\%) who were not operated on died during the admission on the ICU.

In three cases data regarding admission GCS were missed.

\section{Discussion}

Despite the data available from well designed studies, especially from the Surgical Trial in Intracerebral Haemorrhage (STICH), there is incertitude about which is the proper treatment in a particular patient with spontaneous supratentorial intracerebral haemorrhage $3,6,8,15,16,17,18,19,21,22$. The variability among patients, as well as the great number of factors that influence their outcome, are important issues to take into account.

The admission GCS is a well know predictor of outcome in $\mathrm{ICH}^{13,20}$. This fact is also shown in the present study where survival increases progressively with the GCS. For example, 18 of 20 patient with admission GCS of 3 died in the early period and are probably not beneficed by any treatment. Nevertheless, we had 2 who survived, one in the surgical group and the other in the non surgical. This fact may be explained by a misinterpretation of the GCS at admission.
In the patients with admission GCS between 4 and 8 , early mortality was lower in the surgical patients. These patients are probably the most beneficed, at least in terms of early mortality, by the evacuation of the clot through a craniotomy. Disappointingly, in these comatose patients $(\mathrm{GCS}<9)$ sever disability is expected after $\mathrm{ICH}$ as was reported on the $\mathrm{STICH}^{15}$. In the remaining GCS subgroups (patients with GCS on admission between 9 and 15) mortality is lower and there is also a trend that favour surgery on these cases.

The volume of the haematoma is a powerful predictor of outcome in $\mathrm{ICH}^{4,7,13}$. Although, it was just regarded as either more or less than $50 \mathrm{~mL}$ (instead that as a continuous which is more accurate), haematoma volume was also related with mortality in this series. Interestingly, despite that the proportion of patients with large haematomas (greater than $50 \mathrm{~mL}$ ) is higher in the operated cases, they fared better. This fact may suggest that surgery actually beneficed these patients.

One important distinction to note is the haematoma location. In the STICH, the only pre-specified subgroup that showed a significant difference favourable to surgery was the deep of the haematoma ${ }^{15}$. In that trial, patient with haematomas located at one centimetre or less from the cortical surface fared better if operated. As it is show in this series and in others studies $^{10}$, deep-seated ICH has a much worse outcome than superficial $^{12,16}$ and this difference may have therapeutic implications. Although deep-seated location is the most frequent location in most population-based studies ${ }^{9,10,11}$, this was not the case in the present study. One explanation could be that, due to these study is settled among ICU patients and all operated patient are admitted to the ICU, there is an overrepresentation of superficial cases which are more often operated on. On the other hand, low volume basal ganglia haematomas without ventricular extension, which are a frequent type of hypertensive intracerebral bleeding, are underestimated because they are more often selected for conservative treatment, usually in a neurological ward, and so not included in the present study. By contrast, severe ill patients with very large haematomas and with limit treatment measures (do-not-resuscitate orders), a know prognostic factor ${ }^{20}$, are admitted in the ICU as organs donor candidates and included in this study.

In the present cohort, patients with deep haematomas seems to be not beneficed by craniotomy, although there is a tendency in favour to surgery. As it seems rational, deepseated lesion may not be beneficed by a craniotomy, due to the damage necessary during the surgical approach to reach the clot that might offset any advantage ${ }^{6,15,20}$. By contrast, patient with superficial haematomas seems to fare better with surgery in this series. A meta analyses ${ }^{16}$ suggest that patients affected from superficial haematomas are benefited by craniotomy and the European Guidelines ${ }^{20}$ recommend surgery for these patient.

In this study early mortality, defined as dead occurred during the admission on the ICU, was the endpoint. We have 
no data about mortality once the patients were discharged from the ICU. It is well known that deterioration and dead are expected to occur within the first 48 hours of ictus in $\mathrm{ICH}$, when half of deaths use to occur ${ }^{5}$. From that point the probability of dying decreases. In our opinion early mortality, although with caution, may be considered as an indicator of the actual long-term mortality. Another limitation of our study is that we have not considered the performance status of the patient before the ictus neither the outcome in terms of neurological deficit, disability or quality of life of the survivors.

Further studies are needed to establish the role of surgery in ICH patients. Craniotomy is believed to be useful, both to save life and neurological function in some patients, specially in those with lobar haemorrhages, while it may be harmful in others. The current challenge is to identified these patients. An international randomised controlled trial, the STICH II, aimed to answer the question of surgery for patients with superficial haematomas is currently ongoing in and attempt to clarify this point ${ }^{16}$.

\section{References}

1. Badjatia, N., Rosand, J.: Intracerebral hemorrhage. Neurologist 2005; 11: 311-324.

2. Bilbao, G., Garibi, J., Pomposo, I., et al.: A prospective study of a series of 356 patients with supratentorial spontaneous intracerebral haematomas treated in a Neurosurgical Department. Acta Neurochir (Wien ) 2005; 147: 823-829.

3. Broderick, J., Connolly, S., Feldmann, E., et al.: Guidelines for the management of spontaneous intracerebral hemorrhage in adults: 2007 update: a guideline from the American Heart Association/ American Stroke Association Stroke Council, High Blood Pressure Research Council, and the Quality of Care and Outcomes in Research Interdisciplinary Working Group. Stroke 2007; 38: 2001-2023.

4. Broderick, J. P., Brott, T. G., Grotta, J. C.: Intracerebral hemorrhage volume measurement. Stroke 1994; 25: 1081.

5. Broderick, J. P., Adams, H. P., Jr., Barsan, W., et al.: Guidelines for the management of spontaneous intracerebral hemorrhage: A statement for healthcare professionals from a special writing group of the Stroke Council, American Heart Association. Stroke 1999; 30: 905-915.

6. Broderick, J. P.: The STICH trial: what does it tell us and where do we go from here? Stroke 2005; 36: 1619-1620.

7. Broderick, J. P., Brott, T. G., Duldner J. E., et al.: Volume of intracerebral hemorrhage. A powerful and easy-touse predictor of 30-day mortality. Stroke 1993; 24: 987-993.

8. Buckberg, G. D.: Questions and answers about the STICH trial: a different perspective. J Thorac Cardiovasc Surg 2005; 130: 245-249.

9. Flaherty, M. L., Woo, D., Haverbusch, M. et al.: Racial variations in location and risk of intracerebral hemorrhage. Stroke 2005; 36: 934-937.

10. Flaherty, M. L., Haverbusch, M., Sekar, P., et al.: Long- term mortality after intracerebral hemorrhage. Neurology 2006; 66: 1182-1186.

11. Flaherty, M. L., Woo, D., Broderick, J.: The incidence of deep and lobar intracerebral hemorrhage in whites, blacks, and Hispanics. Neurology 2006; 66: 956-957.

12. Hattori, N., Katayama, Y., Maya, Y., Gatherer, A.: Impact of stereotactic hematoma evacuation on medical costs during the chronic period in patients with spontaneous putaminal hemorrhage: a randomized study. Surg Neurol 2006; 65: 429-435.

13. Mayer, S. A., Rincon, F.: Treatment of intracerebral haemorrhage. Lancet Neurol 2005; 4: 662-672.

14. Mayer, S. A., Brun, N. C., Begtrup, K., et al.: Recombinant activated factor VII for acute intracerebral hemorrhage. N Engl J Med 2005; 352: 777-785.

15. Mendelow, A. D., Gregson, B. A., Fernandes, H. M., et al.: Early surgery versus initial conservative treatment in patients with spontaneous supratentorial intracerebral haematomas in the International Surgical Trial in Intracerebral Haemorrhage (STICH): a randomised trial. Lancet 2005; 365: 387-397.

16. Mendelow, A. D., Unterberg, A.: Surgical treatment of intracerebral haemorrhage. Curr Opin Crit Care 2007; 13: 169-174.

17. Pérez-Núñez, A., Lagares, A., Pascual, B., et al.: Tratamiento quirúrgico de la hemorragia intracerebral espontánea. Parte I: Hemorragia supratentorial. Neurocirugía 2008; 19: 12-24.

18. Prasad, K. S., Gregson, B. A., Bhattathiri, P. S., Mitchell, P., Mendelow, A. D.: The significance of crossovers after randomization in the STICH trial. Acta Neurochir Suppl 2006; 96: 61-64.

19. Steiner, T., Diringer, M. N., Schneider, D., et al.: Dynamics of intraventricular hemorrhage in patients with spontaneous intracerebral hemorrhage: risk factors, clinical impact, and effect of hemostatic therapy with recombinant activated factor VII. Neurosurgery 2006; 59: 767-773.

20. Steiner, T., Kaste, M., Forsting, M., et al.: Recommendations for the management of intracranial haemorrhage - part I: spontaneous intracerebral haemorrhage. The European Stroke Initiative Writing Committee and the Writing Committee for the EUSI Executive Committee. Cerebrovasc Dis 2006; 22: 294-316.

21. Teernstra, O.P., Evers, S.M., Kessels, A.H.: Meta analyses in treatment of spontaneous supratentorial intracerebral haematoma. Acta Neurochir (Wien ) 2006; 148: 521-528.

22. Wartenberg, K. E., Mayer, S. A.: The STICH trial: the end of surgical intervention for supratentorial intracerebral hemorrhage? Curr Neurol Neurosci Rep 2005; 5: 473-475.

Samprón, N.; Mendia, A.; Azkarate, B.; Alberdi, F.; Arrazola, M.; Urculo, E.: Early mortality in spontaneous supratentorial intracerebral haemorrhage. Neurocirugía 2010; 21: 93-98.

Correspondencia: Nicolas Samprón. Servicio de Neurocirugía. Hospital Donostia. Paseo Dr. Beguiristain s/n 20080 San Sebastian. España.

E-mail: sampron@neurokirurgia.org 